\section{A flexibilização da legislação brasileira de agrotóxicos e os riscos à saúde humana: análise do Projeto de Lei no 3.200/2015}

The flexibilization of the Brazilian legislation on pesticides and the risks to human health: analysis of Bill of Law 3,200/2015

La flexibilización de la legislación brasileña de agrotóxicos y los riesgos a la salud humana: análisis del Proyecto de Ley no 3.200/2015
Mirella Dias Almeida 1

Thais Araújo Cavendish 1

Priscila Campos Bueno 1

Iara Campos Ervilha 1

Luisa De Sordi Gregório 1

Natiela Beatriz de Oliveira Kanashiro 1

Daniela Buosi Rohlfs 1

Thenille Faria Machado do Carmo 1

doi: 10.1590/0102-311X00181016

\section{Correspondência}

M. D. Almeida

Departamento de Vigilância em Saúde Ambiental e Saúde do Trabalhador, Secretaria de Vigilância em Saúde, Ministério da Saúde.

SRTV 702, Via W5 Norte, Edifício PO 700, 6o andar, Brasília, DF 70719-040, Brasil.

mirellafx@gmail.com

1 Secretaria de Vigilância em Saúde, Ministério da Saúde, Brasília, Brasil. uma análise do Projeto de Lei no 3.200/2015, que representa um dos maiores retrocessos às conquistas legislativas para a regulamentação dos agrotóxicos, de modo a alertar para os riscos à saúde humana frente à exposição a esses produtos e ao agravamento por outras propostas similares.

Agroquímicos; Praguicidas; Legislação; Vigilância Sanitária Ambiental
O presente artigo busca contribuir para uma reflexão sobre a temática dos agrotóxicos, à luz do arcabouço legal brasileiro, na perspectiva da proteção à saúde humana e ao meio ambiente. Tal iniciativa deve-se a sucessivas tentativas de flexibilização das normas de regulação de agrotóxicos no Brasil, por meio de projetos de lei em curso no Congresso Nacional. Para tanto, fez-se 


\section{Introdução}

A partir da década de 1970, o governo brasileiro adotou a monocultura e o uso intensivo de agrotóxicos como política agrícola de modernização no campo, incentivada por meio de isenções fiscais cedidas às indústrias químicas formuladoras de agrotóxicos 1 .

Ao longo dos anos, esse modelo vem causando uma rápida e intensa mudança no uso da terra, produzindo impactos ambientais antes inexistentes, como erosão hídrica e eólica, perda de habitats, alteração dos povoamentos e populações faunísticas, diminuição da vazão dos rios que drenam a região, assoreamento, erosão genética e redução da biodiversidade. Essa situação vem tornando questões como a conservação dos solos e da água cada vez mais relevantes 2 .

Estudos têm demonstrado o desequilíbrio ambiental ocasionado pelo uso de agrotóxicos, que além de desenvolver a capacidade de resistência das pragas agrícolas e estes produtos, levando à necessidade de aumentar as doses aplicadas ou recorrer a novos produtos, tem proporcionado o surgimento de novas pragas e impactando sobre comunidades de insetos controladores de vetores de doenças 3,4,5.

Ademais, não são computados aos gastos públicos os impactos sociais e ambientais de curto, médio e longo prazos, que esse modelo de produção vem ocasionando, como recuperação de áreas contaminadas, prevenção, diagnóstico e tratamento de intoxicações agudas e crônicas, afastamentos e aposentadorias por invalidez de trabalhadores rurais e até mortes 6 .

Segundo o Sistema de Agrotóxicos Fitossanitários (Agrofit) do Ministério da Agricultura, Pecuária e Abastecimento (MAPA), o ano de 2014 registrou a maior quantidade de agrotóxicos comercializados no Brasil desde o início da série histórica (http://agrofit.agricultura.gov.br/primeira_pagina/extra net/AGROFIT.html). Entre 2007 e 2014, esse quantitativo passou de, aproximadamente, 643.057.017 quilos para 1.552.998.056 quilos (equivalente a 141,5\% de aumento) e a área plantada (considerada a soma da lavoura temporária e da lavoura permanente) aumentou de 62.338.730 hectares para 76.246.588 hectares, segundo dados do Sistema de Recuperação Automática (SIDRA) do Instituto Brasileiro de Geografia e Estatística (IBGE) (https://sidra.ibge.gov.br/home/pms/brasil).

Entre os anos de 2007 e 2015, foram notificados 84.206 casos de intoxicação por agrotóxicos no Sistema de Informação de Agravos de Notificação (Sinan), sendo que em 2014 foi identificada a maior incidência de casos, de 6,26 por 100 mil habitantes (http://portalsinan.saude.gov.br/). Apesar de se observar uma melhoria do processo de notificação, a subnotificação é historicamente muito expressiva 7 , em especial das intoxicações crônicas, não permitindo revelar a magnitude do problema no país.

Ressalta-se que, segundo a Portaria GM/MS no 1.271 8, de 6 de junho de 2014, a intoxicação por agrotóxicos faz parte da Lista de Notificação Compulsória (LNC) do Sistema Único de Saúde (SUS), e deve ser notificada semanalmente por meio da ficha de intoxicação exógena do Sinan por médicos, outros profissionais de saúde ou responsáveis pelos serviços públicos e privados de saúde que prestam assistência ao paciente; pelos responsáveis por estabelecimentos públicos ou privados educacionais, de cuidado coletivo, além de serviços de hemoterapia, unidades laboratoriais e instituições de pesquisa.

A subnotificação das intoxicações, além de invisibilizar os custos para o SUS, já que estas podem se manifestar de formas clínicas diversas, tem colaborado para inviabilizar ações de vigilância e impedir o acesso dos trabalhadores aos seus direitos e à informação da sua real situação de saúde 9 .

A exposição aos agrotóxicos ocorre, principalmente, no setor agropecuário, nas atividades de controle de vetores em saúde pública, nas empresas desinsetizadoras e durante o transporte, a comercialização e a produção de agrotóxicos. Além da exposição ocupacional, destaca-se a contaminação alimentar e ambiental, que coloca em risco a saúde de outros grupos populacionais, como as famílias dos agricultores, a população circunvizinha a uma unidade produtiva e a população em geral que se alimenta do que é produzido no campo 10.

Diante desse quadro, é essencial que todas as esferas de governo adotem medidas, de acordo com as suas respectivas competências estabelecidas na Lei no 7.802/198911 e regulamentadas no Decreto no 4.074/2002 12, para garantir o cumprimento da legislação e, por consequente, a proteção à saúde humana, animal e ao meio ambiente.

Para tanto, é necessária uma atuação eficaz dos órgãos responsáveis que atuam nas áreas da saúde, do meio ambiente e da agricultura responsáveis pelo registro, avaliação e fiscalização da cadeia produtiva dos agrotóxicos. 
Tais cuidados e exigências decorrem da toxicidade intrínseca que essas substâncias representam à saúde humana e ao meio ambiente. Adicionalmente, existem iniciativas diversas de aprimoramento da restrição e do controle do uso de agrotóxicos, a exemplo do que pretende o Programa Nacional para Redução de Agrotóxicos (PRONARA) 13. Esse Programa, ainda não publicado, foi concebido como uma das metas da Política Nacional de Agroecologia e Produção Orgânica (PNAPO) 14, que visa a ampliar e efetivar as ações promotoras do desenvolvimento rural sustentável.

Questões como o combate ao contrabando de agrotóxicos e a importação de produtos não permitidos no país 15,16; descumprimento frequente pelas empresas das normas de regulação da pulverização aérea 17,18,19,20,21; intoxicação aguda e crônica da população 22,23,24,25; irregularidades na presença de resíduos de agrotóxicos em água para o consumo humano e alimentos 26,27,28,29,30; falta de informação ao consumidor da presença de agrotóxicos nos alimentos 31 ; imposição aos trabalhadores/as agrícolas da adoção do modelo de produção convencional (obtenção de crédito rural condicionante ao uso de agrotóxicos) sem assistência técnica adequada e suficiente 6,32,33; diminuição da população de insetos, como abelhas, essenciais para a polinização de várias plantas e aumento de pragas resistentes aos agrotóxicos 3,5,34, são questões urgentes para aprimorar o controle e o monitoramento da cadeia produtiva destes produtos e garantir a proteção à saúde da população e ao meio ambiente.

Essas pautas demonstram as fragilidades e as arbitrariedades da utilização de agrotóxicos no país, evidenciando a necessidade de investimento nos órgãos de controle e fiscalização, com incremento de pessoal e tecnologia. Na contramão desse cenário, observa-se a existência de diversas propostas de Projeto de Lei (PL) no Congresso Nacional, tais como PL 3.215/2000, PL 5.852/2001, PL 6.299/2002, PL 6.189/2005, PL 1.176/2015 e o PL 3.200/2015 objeto de análise deste artigo.

O PL 3.200/2015 “dispõe sobre a Política Nacional de Defensivos Fitossanitários e de Produtos de Controle Ambiental, seus Componentes e Afins, bem como sobre a pesquisa, a experimentação, a produção, a embalagem e rotulagem, o transporte, o armazenamento, a comercialização, a propaganda comercial, a utilização, a importação, a exportação, o destino final dos resíduos e embalagens, o registro, a classificação, o controle, a inspeção e a fiscalização de defensivos fitossanitários e de produtos de controle ambiental, seus componentes e afins, $e$ dá outras providências" (http://www.camara.gov.br/proposicoesWeb/fichadetramitacao?idProposi cao $=1996620$ ).

Nesse sentido, o artigo busca contribuir para uma reflexão sobre a temática dos agrotóxicos, à luz do arcabouço legal brasileiro e das consequências da desregulamentação em curso no Congresso Nacional, na perspectiva da proteção à saúde humana e ao meio ambiente.

\section{PL 3.200/2015 e a tentativa de desregulamentação da Lei de Agrotóxicos}

Os agrotóxicos no Brasil são regidos pela Lei no 7.802/1989, regulamentada pelo Decreto no 4.074/2002 que substituiu os decretos no 24.114/1934 e no 98.816/1990. Essa normatividade é considerada uma das mais avançadas e protetoras da saúde humana e do meio ambiente existentes no mundo, por introduzir critérios ambientais, de saúde pública e de desempenho agronômico, considerados mais rígidos para os registros de agrotóxicos 16,35,36.

Todavia, são apresentados, a seguir, os termos propostos pelo PL em pauta para a alteração da lei supracitada, que representam um retrocesso às conquistas legislativas.

\section{Substituição da terminologia "agrotóxicos"}

No Art. 5, Capítulo II, agrotóxico é denominado como "produto defensivo fitossanitário", o que permite minimizar ou mesmo anular a percepção de toxicidade intrínseca que essas substâncias representam à saúde humana e ao meio ambiente, transmitindo uma ideia de que são inofensivos. Os agrotóxicos podem produzir efeitos deletérios à saúde que variam com o princípio ativo, a dose absorvida, a forma de exposição e as características individuais da pessoa exposta. As consequências descritas na literatura compreendem alergias; distúrbios gastrintestinais, respiratórios, endócrinos, reprodutivos e neurológicos; neoplasias; mortes acidentais; e suicídios 23 .

É apresentado na Figura 1 o comparativo da definição de agrotóxicos na lei vigente e no PL $3.200 / 2015$. 
Agrotóxicos e afins: produtos e os agentes de processos físicos, químicos ou biológicos, destinados ao uso nos setores de produção, no armazenamento e beneficiamento de produtos agrícolas, nas pastagens, na proteção de florestas, nativas ou implantadas, e de outros ecossistemas e também de ambientes urbanos, hídricos e industriais, cuja finalidade seja alterar a composição da flora ou da fauna, a fim de preservá-las da ação danosa de seres vivos considerados nocivos.
Produto defensivo fitossanitário: produto e agente de processos físicos químicos ou biológicos, destinado ao uso nos setores de produção, no armazenamento e beneficiamento de produtos agrícolas, nas pastagens, na proteção de florestas plantadas cuja finalidade seja alterar a composição da flora ou da fauna, a fim de preservá-las da ação danosa de seres vivos considerados nocivos.

Produto de controle ambiental: produto e agente de processos físicos, químicos ou biológicos, destinado ao uso nos setores de proteção de florestas nativas ou de outros ecossistemas e de ambientes hídricos, cuja finalidade seja alterar a composição da flora ou da fauna, a fim de preservá-las da ação danosa de seres vivos considerados nocivos.

Os produtos e agentes de processos físicos, químicos ou biológicos, destinados ao uso nos setores de proteção de florestas nativas ou de outros ecossistemas e de ambientes hídricos tornam-se "produtos de controle ambiental". O termo "florestas implantadas" também fica excluído da legislação.

\section{Perda do poder de decisão dos Ministérios da Saúde e do Meio Ambiente}

O Capítulo III traz diversas questões polêmicas, dentre as quais se destacam os seguintes trechos: (a) Art. 6o: "Fica autorizada a criação, no âmbito do Ministério da Agricultura, Pecuária e Abastecimento, a Comissão Técnica Nacional de Fitossanitários - CTNFito, instância colegiada multidisciplinar de caráter consultivo e deliberativo, com a finalidade de apresentar pareceres técnicos conclusivos aos pedidos de avaliação de novos produtos defensivos fitossanitários, de controle ambiental, seus produtos técnicos e afins"; (b) Parágrafo único: "CTNFito deverá acompanhar o desenvolvimento e o progresso técnico e científico nas áreas de segurança e tecnologia, com o objetivo de garantir a proteção da saúde humana, dos animais, das plantas e do meio ambiente”; e (c) Art. 7: a "CTNFito será composta por vinte e três membros efetivos e respectivos suplentes, designados pelo Ministro de Estado da Agricultura, Pecuária e Abastecimento...”.

Ressalta-se que atualmente a responsabilidade de avaliar, reavaliar e registrar agrotóxicos cabe às três instituições (MAPA, Ministério da Saúde e Ministério do Meio Ambiente - MMA), de forma autônoma, sendo o MAPA responsável apenas pelo que lhe compete, a avaliação do desempenho agronômico dos agrotóxicos; ao Ministério da Saúde compete a avaliação toxicológica; e ao MMA, a avaliação ambiental, cujas atribuições estão detalhadamente no Decreto no 4.074/2002. O registro é concedido somente após o deferimento do parecer dos três órgãos, sendo que a preocupação com a saúde e o meio ambiente sempre devem prevalecer. Sendo assim, o PL propõe uma concentração de poder no âmbito da CTNFito, vinculada ao MAPA, excluindo diversas atribuições específicas do Ministério da Saúde e MMA.

Ademais, a CTNFito estabelece uma composição que altera completamente essa disposição de poderes. Cita em seu Art. 19 que as "decisões serão tomadas com votos favoráveis da maioria absoluta de seus membros”. Avaliando essa composição, verifica-se a que se reduz a participação do Ministério da Saúde na tomada de decisão como membro da Comissão:

- 15 especialistas de notório saber científico e técnico (provavelmente de instituições públicas e privadas);

- 1 representante de cada órgão de registro e fiscalização (MAPA, Ministério do Desenvolvimento, Indústria e Comércio - MDIC, MMA, Ministério da Saúde e Ministério da Ciência, Tecnologia e Inovação - MCTI); 
- 1 representante de órgão legalmente constituído de proteção à saúde do trabalhador;

- 1 representante de órgão legalmente instituído representativo do produtor rural;

- 1 representante de associações legalmente constituídas de produtores de defensivos fitossantinários.

\section{Perda de autonomia dos estados}

A legislação vigente permite que estados e Distrito Federal constituam leis próprias de regulação dos agrotóxicos. Entretanto, o PL 3.200/2015 modifica essa garantia ao permitir a competência de legislar sobre o uso, a produção, o consumo, o comércio e o armazenamento dos agrotóxicos, seus componentes e afins, bem como fiscalizar o uso, o consumo, o comércio, o armazenamento e o transporte interno, apenas de forma suplementar à União. Ainda, veta aos estados e Distrito Federal, conforme o Art. 24, do Capítulo V (Figura 2), restringir o alcance do registro federal, a menos que seja para atender uma particularidade regional devidamente justificada. Outra questão que surge é a fragilidade da avaliação dessa justificativa, por não ser definido o parâmetro para a aceitação das particularidades apresentadas pelos entes federados.

Ainda sobre a questão citada, o PL 3.200/2015 suprime dos estados e do Distrito Federal a competência de fiscalizar o consumo e o comércio, conforme o Art. 26 transcrito na Figura 2. Tal proposta agravará a venda de agrotóxicos ilegais e a exposição dos trabalhadores e da população a estes produtos.

\section{Flexibilização dos casos de proibição dos registros}

O PL 3.200/2015 permite a flexibilização dos casos de proibição dos registros de agrotóxicos. A título de exemplificação, a Lei no 7.802/1989 proíbe o registro de agrotóxico se este apresentar características teratogênicas, carcinogênicas, mutagênicas, de acordo com os resultados atualizados de experiências da comunidade científica; distúrbios hormonais, danos ao aparelho reprodutor; e produtos que se apresentem mais perigosos para o homem do que os testes de laboratório com animais. Já o PL $3.200 / 2015$ permite a continuidade de uso, proibindo o produto apenas quando este revelar um risco inaceitável, além de não definir o que é risco aceitável e inaceitável.

\section{Figura 2}

Comparativo da Lei no 7.802/1989 com o Projeto de Lei no 3.200/2015.

\section{LEI 7.802/1989}

Art. 9o No exercício de sua competência, a União adotará as seguintes providências:

I - legislar sobre a produção, registro, comércio interestadual, exportação, importação, transporte, classificação e controle tecnológico e toxicológico;

II - controlar e fiscalizar os estabelecimentos de produção, importação e exportação;

III - analisar os produtos agrotóxicos, seus componentes e afins, nacionais e importados;

IV - controlar e fiscalizar a produção, a exportação e a importação.

Art. 10ㅇ Compete aos Estados e ao Distrito Federal, nos termos dos art. 23 e 24 da Constituição Federal, legislar sobre o uso, a produção, o consumo, o comércio e o armazenamento dos agrotóxicos, seus componentes e afins, bem como fiscalizar o uso, o consumo, o comércio, o armazenamento e o transporte interno.

\section{PL 3.200/2015}

Art. 24으 No exercício de sua competência, a União adotará as seguintes providências:

I - legislar sobre a produção, registro, comércio interestadual, exportação, importação, transporte, classificação e controle tecnológico, ambiental e toxicológico;

II - controlar e fiscalizar os estabelecimentos de produção, importação e exportação;

III - analisar os produtos defensivos fitossanitários e de controle

ambiental, seus componentes e afins, nacionais e importados;

IV - controlar e fiscalizar a produção, a exportação, a importação e o transporte interestadual.

Art. 26o Compete aos Estados e ao Distrito Federal, nos termos dos art. 23 e 24 da Constituição Federal, legislar supletivamente sobre

o uso, o comércio e o armazenamento de produtos defensivos fitossanitários e de controle ambiental, seus componentes e afins, bem como fiscalizar o uso, o armazenamento e o transporte interno. 
As considerações a seguir esclarecem a impossibilidade de se estabelecer um risco inaceitável:

- A Organização Mundial da Saúde (OMS) estabelece que se uma substância é considerada comprovadamente carcinogênica para animais, deve também ser tratada como tal para seres humanos, principalmente se também tem ação genotóxica (mutagênica, ou seja, apresentar mutações dos genes). Frequentemente considera-se que uma única molécula capaz de produzir efeito adverso, como câncer ou mutação genética, é suficiente para iniciar um processo que, progressivamente, pode levar ao efeito prejudicial observado. Por essa razão, não é possível demonstrar que existe um limite seguro de exposição para um agente causador de câncer (carcinogênico) ou de mutação genética (mutagênico) 37 . Portanto, não existe a possibilidade de estabelecer parâmetro de "risco inaceitável" para substâncias genotóxicas.

- Ademais, os estudos em animais relativos à ação de substâncias sobre o sistema endócrino são, na grande maioria, feitos com uma substância. Porém, a exposição humana ocorre a várias substâncias, inclusive para o uso de agrotóxicos. Diante disso, não é possível estabelecer risco sob as condições atuais, pois não existem estudos sobre o efeito da exposição a múltiplas substâncias. Isso também ocorre para os casos de câncer, malformações etc.

- Cita-se ainda que os efeitos (como câncer, malformações congênitas etc.) de todas as substâncias com ação mutagênica podem ocorrer na prole da população exposta. Isso significa que "limitar a exposição a adultos" não é indicativo de segurança ou proteção de grupos populacionais mais vulneráveis, como crianças, por exemplo.

Um desregulador endócrino é uma substância química exógena ou uma mistura de substâncias que altera a estrutura ou as funções do sistema endócrino, resultando em efeitos adversos no organismo, na prole, em populações ou subpopulações. Em 2012, o Programa das Nações Unidas para o Meio Ambiente (UNEP) e a OMS no documento State of the Science of Endocrine Disrupting Chemicals (2012) 38 definiram como diretrizes que o sistema endócrino é semelhante nos vertebrados, portanto, os efeitos endócrinos se manifestam independentemente da espécie, ou seja, estes efeitos não são necessariamente espécie dependente. Os efeitos observados em animais selvagens ou de experimentos podem ocorrer nos humanos expostos, tendo especial atenção para efeitos nos períodos iniciais do desenvolvimento humano e da fauna. Esses efeitos são irreversíveis ou aparecem tardiamente na vida. Os desreguladores endócrinos por diversos mecanismos mostram curvas dose-resposta não lineares in vivo e in vitro, e nas últimas duas décadas foi estabelecido que os desreguladores endócrinos podem atuar conjuntamente e causar efeitos aditivos, mesmo em combinações de baixas doses que individualmente não mostrariam efeitos.

- Risco por definição significa "probabilidade de ocorrência”. A inclusão da expressão risco inaceitável significa que o PL 3.200/2015 considerara como aceitável a ocorrência de um determinado número de efeitos. Entretanto, não existe possibilidade de estabelecer um valor considerado como aceitável para a ocorrência de malformações congênitas, câncer etc. nas populações expostas e em sua prole.

\section{Incoerências do texto e flexibilização do uso de agrotóxicos}

O Art. 54, do Capítulo IX, sobre a comercialização, das embalagens, dos rótulos e das bulas cita em seu $\$ 1$ o que "o profissional habilitado poderá prescrever receita agronômica antes da ocorrência da praga, de forma preventiva, visando o controle de alvos biológicos que necessitam de aplicação de produto defensivo fitossanitário $e$ de controle ambiental e afim". A aplicação preventiva contribui para o uso intensivo de agrotóxico, empobrece a biodiversidade benéfica às culturas, gerando resistências de espécies aos agrotóxicos, além de contribuir para a contaminação do solo, das águas, pela lixiviação e carregamento destes compostos, e dos trabalhadores pela bioacumulação ao longo do tempo 39.

A literatura recomenda a utilização de técnicas de monitoramento e controle de pragas e doenças que considerem a ação dos agentes naturais de controle biológico, dentro de um contexto ecológico, toxicológico, ambiental e social, visando a racionalizar o uso de agrotóxicos 40 . Ainda sobre essa questão, Futino \& Silveira (1991, apud Alves Filho 1) já observavam o círculo vicioso decorrente do aumento do número de pragas, a partir do incremento do uso preventivo de agrotóxicos, associado à política de crédito agrícola adotada no Brasil na década de 1970.

O Art. 60, do Capítulo IX, indica que a "propaganda comercial de produtos defensivos fitossanitários, de controle ambiental e afins, em qualquer meio de comunicação, obedecerá a legislação específica vigente”, retirando a obrigatoriedade de todas as precauções citadas na Lei no 7.802/1989. 
O Art. 61, do Capítulo X, sobre armazenamento e transporte, suprime a exigência constante no Decreto $n$ o 4.074/2002, de obediência às normas municipais aplicáveis, inclusive quanto à edificação e à localização.

O Art. 43, do Capítulo VI, permite a criação da Permissão Experimental Temporária (PET) para novos produtos a ser expedida quando se destinar à pesquisa e à experimentação e será avaliada $\mathrm{e}$ autorizada pela CTNFito. Atualmente, existe o Registro Especial Temporário (RET) cuja concessão está sujeita à aprovação do MAPA, da Agência Nacional de Vigilância Sanitária (Anvisa) e do Instituto Brasileiro do Meio Ambiente e dos Recursos Naturais Renováveis (Ibama), segundo suas competências. Essa alteração repercute nas mesmas questões apontadas no item referente à criação da CTNFito.

Diante da gravidade da situação, diversas entidades já se manifestaram contrárias ao disposto no PL 3.200/2015, como: Ministério Púbico Federal (MPF) 41, Conselho de Segurança Alimentar e Nutricional (CONSEA) 42, Fórum Gaúcho de Combate aos Impactos dos Agrotóxicos 43 e Rede Nacional de Advogadas e Advogados Populares (RENAP) 44.

Vale lembrar que o Brasil é signatário da Convenção sobre Procedimento de Consentimento Prévio Informado para o Comércio Internacional de Certas Substâncias Químicas e Agrotóxicos Perigosos, adotada em 10 de setembro de 1998, na cidade de Roterdã, Holanda, cuja adesão se deu por meio do Decreto no 5.360/2005 45. A Convenção objetiva promover a responsabilidade compartilhada e os esforços cooperativos entre as Partes no comércio internacional de certas substâncias químicas perigosas, visando à proteção da saúde humana e do meio ambiente contra danos potenciais, e contribuir para o uso ambientalmente correto desses produtos, facilitando o intercâmbio de informações sobre suas características, estabelecendo um processo decisório nacional para a sua importação e exportação e divulgando estas decisões às Partes.

Por fim, vale ressaltar que na perspectiva da sustentabilidade da agricultura, a rentabilidade econômica de um sistema de produção não é suficiente para compensar os gastos ecológicos e sociais gerados. Atualmente, desempenho técnico consiste na combinação da eficácia econômica, com gastos ecológicos mínimos para a sociedade atual e futuras gerações, incluindo a participação equitativa de todos(as) agricultores(as) nos frutos do desenvolvimento de um território. A harmonia dessa combinação em um sistema técnico-econômico-ambiental coerente é que permite a sustentabilidade em um determinado agroecossistema 46 .

\section{Considerações finais}

Feitas estas considerações, observa-se que o PL 3.200/2015 preza por questões econômicas do mercado produtor de agrotóxicos e contribuirá para maximizar os impactos sociais e ambientais de curto, médio e longo prazos, gerados pelo uso indiscriminado de agrotóxicos, a serem custeados por toda a população.

O PL 3.200/2015 figura um retrocesso às conquistas legislativas, suprimindo conceitos importantes da Lei no 7.802/1989, como uma manobra para fragilizar ainda mais a fiscalização e o registro dos agrotóxicos mais utilizados do país.

A exposição humana a esses produtos representa, portanto, um problema de saúde pública que certamente será agravado nos termos propostos, ferindo a própria Constituição Federal, que estabelece o Estado como garantidor da redução do risco de doença e de outros agravos mediante políticas sociais e econômicas. 


\section{Colaboradores}

M. D. Almeida redigiu o artigo. T. A. Cavendish, P. C. Bueno, L. D. S. Gregório, I. C. Ervilha e D. B. Rohlfs revisaram criticamente o conteúdo. N. B. O. Kanashiro e T. F. M. Carmo contribuíram com a análise e interpretação dos dados e revisaram criticamente o conteúdo.

\section{Agradecimentos}

Ivonne Natalia Solarte Agredo, Renan Duarte dos Santos e Débora de Sousa Bandeira pelo levantamento das referências bibliográficas.

\section{Referências}

1. Alves Filho JP. Receituário agronômico: a construção de um instrumento de apoio à gestão dos agrotóxicos e sua controvérsia [Dissertação de Mestrado]. São Paulo: Programa de Pós-graduação em Ciência Ambiental, Universidade de São Paulo; 2000.

2. Batistella M, Guimarães M, Miranda E, Vieira HR, Valladares GS, Mangabeira JAC, et al. Monitoramento da expansão agropecuária na região oeste da Bahia. Campinas: Embrapa Monitoramento por Satélite; 2002.

3. Ferreira MLPC. A pulverização aérea de agrotóxicos no Brasil: cenário atual e desafios. Rev Direito Sanit 2015; 15:18-45.

4. Peres F, Moreira JC. Saúde e ambiente em sua relação com o consumo de agrotóxicos em um pólo agrícola do Estado do Rio de Janeiro, Brasil. Cad Saúde Pública 2007; 23 Suppl 4: S612-21.

5. Moreira JC, Jacob SC, Peres F, Lima JS, Meyer A, Oliveira-Silva JJ, et al. Avaliação integrada do impacto do uso de agrotóxicos sobre a saúde humana em uma comunidade agrícola de Nova Friburgo - RJ. Ciênc Saúde Coletiva 2002; 7:299-311.

6. Abreu PHB. O agricultor familiar e o uso (in) seguro de agrotóxicos no Município de Lavras - MG [Dissertação de Mestrado]. Campinas: Faculdade de Ciências Médicas, Universidade Estadual de Campinas; 2014.

7. World Health Organization. Public health impact of pesticides used in agriculture. Geneva: World Health Organization; 1990.

8. Ministério da Saúde. Portaria no 1.271, de 6 de junho de 2014. Define a Lista Nacional de Notificação Compulsória de doenças, agravos e eventos de saúde pública nos serviços de saúde públicos e privados em todo o território nacional, nos termos do anexo, e dá outras providências. Diário Oficial da União 2014; 9 jun.

9. Centro Estadual de Saúde do Trabalhador, Superintendência de Vigilância em Saúde, Secretaria de Estado da Saúde. Protocolo de avaliação das intoxicações crônicas por agrotóxicos. http://www.saude.pr.gov.br/arquivos/File/ CEST/Protocolo_AvaliacaoIntoxicacaoAgro toxicos.pdf (acessado em 11/Jul/2016).

10. Silva JM, Novato-Silva E, Faria HP, Pinheiro TMM. Agrotóxico e trabalho: uma combinação perigosa para a saúde do trabalhador rural. Ciênc Saúde Coletiva 2005; 10:891-903.

11. Brasil. Lei no 7.802, de 11 de julho de 1989. Dispõe sobre a pesquisa, a experimentação, a produção, a embalagem e rotulagem, o transporte, o armazenamento, a comercialização, a propaganda comercial, a utilização, a importação, a exportação, o destino final dos resíduos e embalagens, o registro, a classificação, o controle, a inspeção e a fiscalização de agrotóxicos, seus componentes e afins, e dá outras providências. Diário Oficial da União 1989; 12 jul. 
12. Brasil. Decreto no 4.074 , de 4 de janeiro de 2002. Regulamenta a Lei no 7.802 , de 11 de julho de 1989, que dispõe sobre a pesquisa, a experimentação, a produção, a embalagem e rotulagem, o transporte, o armazenamento, a comercialização, a propaganda comercial, a utilização, a importação, a exportação, o destino final dos resíduos e embalagens, o registro, a classificação, o controle, a inspeção e a fiscalização de agrotóxicos, seus componentes e afins, e dá outras providências. Diário Oficial da União 2002; 8 jan.

13. Presidência da República. Proposta Pronara - Programa Nacional de Redução de Agrotóxicos. http://www.asabrasil.org.br/images/ UserFiles/File/CartilhaANA_Pronara.pdf (acessado em 11/Jul/2016).

14. Brasil. Decreto no 7.794 , de 20 de agosto de 2012. Institui a Política Nacional de Agroecologia e Produção Orgânica. Diário Oficial da União 2012; 21 ago.

15. Da Ros JR. Falsificação e contrabando de agrotóxicos: a sociedade perde a saúde, o país perde o respeito. http://www.cnpa.embrapa. br/produtos/algodao/publicacoes/trabalhos_ cba5/320.pdf (acessado em 11/Jul/2016).

16. Vaz PAB. Crimes de agrotóxicos. Revista de Doutrina da 4a Região 2005; (8). http://bdjur. stj.jus.br/jspui/bitstream/2011/62621/crimes_agrotoxicos.pdf.

17. Londres F. Agrotóxicos no Brasil: um guia para ação em defesa da vida. Rio de Janeiro: Assessoria e Serviços a Projetos em Agricultura Alternativa; 2011.

18. Rigotto RM, organizador. Agrotóxicos, trabalho e saúde: vulnerabilidades, resistência no contexto da modernização agrícola no Baixo Jaguaribe - CE. Fortaleza: Edições UFC/Expressão Popular; 2011.

19. Pignatii WA, Machado JMH, Cabral JF. Acidente rural ampliado: o caso das "chuvas" de agrotóxicos sobre a Cidade de Lucas do Rio Verde - MT. Ciênc Saúde Coletiva 2007; 12:105-14.

20. Marinho AMCP, Carneiro FF, Almeida VE. Dimensão socioambiental em área de agronegócio: a complexa teia de riscos, incertezas e vulnerabilidades. In: Rigotto RM, organizador. Agrotóxicos, trabalho e saúde: vulnerabilidade e resistência no contexto da modernização agrícola no Baixo Jaguaribe - CE. Fortaleza: Edições UFC/Expressão Popular; 2011. p. 166-216.

21. Machado P. Um avião contorna o pé de jatobá e a nuvem de agrotóxico pousa na cidade. Brasília: Agência Nacional de Vigilância Sanitária; 2008.

22. Faria NMX, Fassa AG, Facchini LA. Intoxicação por agrotóxicos no Brasil: os sistemas oficiais de informação e desafios para realização de estudos epidemiológicos. Ciênc Saúde Coletiva $2007 ; 12: 25-38$.

23. World Health Organization. Exposure to highly hazardous pesticides: a major public health concern. Geneva: World Health Organization; 2010 .
24. Instituto Nacional de Câncer José Alencar Gomes da Silva. Posicionamento do Instituto $\mathrm{Na}$ cional de Câncer José Alencar Gomes da Silva acerca dos agrotóxicos. http://www1.inca. gov.br/inca/Arquivos/comunicacao/posiciona mento_do_inca_sobre_os_agrotoxicos_06_ abr_15.pdf (acessado em 11/Jul/2016).

25. Oliveira SM, Gomes TCC. Contaminação por agrotóxico em população de área urbana - Petrópolis, RJ. Cad Saúde Pública 1990; 6:18-26.

26. Secretaria de Vigilância em Saúde, Ministério da Saúde. Monitoramento de agrotóxicos na água para consumo humano no Brasil, 2011. Boletim Epidemiológico 2013; 44(10). http:// portalsaude.saude.gov.br/images/pdf/2014/ maio/09/Boletim-Epidemiol--gico-Monitora mento-de-agrot--xicos-na---gua-para-consu mo-humano-no-Brasil-2011-.pdf.

27. Secretaria de Vigilância em Saúde, Ministério da Saúde. Monitoramento de agrotóxicos na água para consumo humano no Brasil, 2011/2012. Boletim Epidemiológico 2013; 44(17). http://u.saude.gov.br/images/ pdf/2014/junho/11/BE-2013-44--17--.Agrot--xicos.pdf.

28. Secretaria de Vigilância em Saúde, Ministério da Saúde. Monitoramento de agrotóxicos na água para consumo humano no Brasil, 2013. Boletim Epidemiológico 2015; 46(4). http:// portalsaude.saude.gov.br/images/pdf/2015/ agosto/20/2014-028---Boletim-Agrotoxico-. pdf.

29. Secretaria de Vigilância em Saúde, Ministério da Saúde. Monitoramento de agrotóxicos na água para consumo humano no Brasil, 2014. Boletim Epidemiológico 2016; 47(12). http:// portalsaude.saude.gov.br/images/pdf/2016/ abril/08/Monitoramento-de-agrot--xicosem---gua-para-consumo-humano--Bra sil---2014.pdf.

30. Agência Nacional de Vigilância Sanitária. Programa de Análise de Resíduos de Agrotóxicos em Alimentos (PARA) - relatório de atividades de 2011 e 2012. http://portal. anvisa.gov.br/wps/wcm/connect/d480f5 0041 ebb7a09db8bd3e2b7e7e4d/Relat\% C $3 \%$ B 3 rio\% 2 B PARA\% 2 B $2011-12 \% 2$ B \%2B30_10_13_1.pdf?MOD=AJPERES (acessado em $11 / \mathrm{Jul} / 2016$ ).

31. Freire Júnior AB, Viana Filho JS. O uso abusivo de agrotóxicos frente ao direito do consumidor. Revista Âmbito Jurídico 2013. http://www.ambito-juridico.com.br/ site/?n_link=revista_artigos_leitura\&artigo_ $\mathrm{id}=13142$.

32. Bülow AE. Agrotóxicos e políticas públicas: práticas e contradições no Município de Novo Cabrais - RS [Dissertação de Mestrado]. Santa Maria: Universidade Federal de Santa Maria; 2008. 
33. Sznitowski AM, Menegon NL. Comportamento adotado pelos agricultores familiares no uso e manuseio de agrotóxicos: um estudo de caso no Assentamento Guapirama, em Campo Novo do Parecis-MT. Revista GEPROS: Gestão da Produção, Operações e Sistemas 2012; 7:51-64.

34. Empresa Brasileira de Pesquisa Agropecuária. Agricultura de precisão: resultados de um novo olhar. Brasília: Empresa Brasileira de Pesquisa Agropecuária; 2014.

35. Silva L. Histórico da regulamentação dos agrotóxicos. Brasília: Agência Nacional de Vigilância Sanitária; 2007. (Texto para Discussão).

36. Pelaez V, Terra FHB, Silva LR. A regulamentação dos agrotóxicos no Brasil: entre o poder de mercado e a defesa da saúde e do meio ambiente. Revista de Economia 2010; 36:27-48.

37. Organização Mundial da Saúde. Programa Internacional de Segurança Química. Substâncias químicas perigosas à saúde e ao ambiente. São Paulo: Cultura Acadêmica; 2008.

38. United Nations Environment Programme/ World Health Organization. State of the science of endocrine disrupting chemicals - 2012. Geneva: World Health Organization; 2013.

39. Freitas JAD, Lima JR, Nassu RT, Bastos MSR. Manual de boas práticas agrícolas e sistemas APPCC para o melão. Fortaleza: EMBRAPA Agroindústria Tropical; 2005.

40. Empresa Brasileira de Pesquisa Agropecuária. Manual de segurança e qualidade para a cultura do melão. Brasília: Empresa Brasileira de Pesquisa Agropecuária; 2004.

41. Ministério Público Federal. Nota de repúdio ao Projeto de Lei no 3200/2015. http:// www.mpf.mp.br/pgr/documentos/Nota_rep dio_3.200.pdf (acessado em 15/Jul/2016).
42. Conselho Nacional de Segurança Alimentar e Nutricional. Exposição de motivos no 04/2016. http://www.contraosagrotoxicos.org/images/ EM_004_Agrotxico_PL3200.15-e-6299.02. pdf (acessado em 15/Jul/2016).

43. Fórum Gaúcho de Combate aos Impactos dos Agrotóxicos. Nota de repúdio ao PL no3200/2015. https://www.mprs.mp.br/areas/ ambiente/arquivos/agrotoxicos/forum_agro tox/nota_de_repudio_pl_3200_2015.pdf (acessado em 15/Jul/2016).

44. Rede Nacional de Advogadas e Advogados Populares. Moções de repúdio aprovadas no XX Encontro Nacional da RENAP. http:// acervo.racismoambiental.net.br/2015/12/01/ mocoes-de-repudio-aprovadas-no-xx-en contro-nacional-da-renap/ (acessado em 15/ Jul/2016).

45. Brasil. Decreto no 5.360 de 31 de janeiro de 2005. Promulga a Convenção sobre Procedimento de Consentimento Prévio Informado para o Comércio Internacional de Certas Substâncias Químicas e Agrotóxicos Perigosos, adotada em 10 de setembro de 1998, na cidade de Roterdã. Diário Oficial da União 2005; 1 fev.

46. Bianchini V, Medaet JPP. Da revolução verde à agroecologia: Plano Brasil Agroecológico. http://www.mda.gov.br/portalmda/sites/ default/files/user_arquivos_195/Brasil\%20 Agroecol\%C3\%B3gico\%2027-11-13\%20Arti go\%20Bianchini\%20e\%20Jean\%20Pierre.pdf (acessado em 22/Jul/2016). 


\section{Abstract}

This article aims to contribute to a reflection on pesticides, based on the Brazilian legal framework, from the perspective of protecting human health and the environment. This initiative is due to successive attempts to flexibilize the regulation of pesticides in Brazil, through bills of law in progress in the Brazilian National Congress. An analysis of Bill of Law 3,200/2015 was carried out. This bill of law represents a major setback to the legislative achievements for the regulation of pesticides, in order to alert to the risks to human health from exposure to these products and aggravated by other similar proposals.

Agrochemicals; Pesticides; Legislation; Environmental Health Surveillance

\section{Resumen}

El presente artículo busca contribuir a una reflexión sobre la temática de los agrotóxicos, a la luz del marco legal brasileño, desde la perspectiva de proteger la salud humana y el medio ambiente. Esta iniciativa se debe a sucesivos intentos de flexibilización de las normas de regulación de agrotóxicos en Brasil, a través de proyectos de ley en curso en el Congreso Nacional. Se llevó a cabo un análisis del Proyecto de Ley no 3.200/2015, que representa uno de los mayores retrocesos a las conquistas legislativas para la normativa de los agrotóxicos, para alertar sobre los riesgos a la salud humana frente a la exposición a esos productos $y$ al agravamiento por otras propuestas similares.

Agroquímicos; Plaguicidas; Legislación;

Vigilancia Sanitaria Ambiental 